\title{
PARTICIPAÇÃO DOS TRABALHADORES NOS \\ LUCROS E RESULTADOS DAS EMPRESAS: \\ LIÇÕES DA EXPERIÊNCIA INTERNACIONAL*
}

\author{
Daniela Corrêa ${ }^{* *}$
}

Gilberto Tadeu Lima

RESUMO Resgata-se a evidência empírica internacional sobre efeitos de esquemas de participação dos trabalhadores nos lucros e resultados das empresas, o que permite mostrar que a experiência brasileira, ainda pouco estudada, oferece indícios que vão ao encontro das opiniões de que esses esquemas podem melhorar os indicadores das empresas que os adotam e as relações no ambiente de trabalho. Com base em dados sobre experiências de sucesso de alguns países, são apontadas algumas possíveis direções para onde o caso brasileiro poderia caminhar, sendo abordado inclusive o papel de políticas públicas de incentivo aos esquemas de participação.

Palavras-chave: participação nos lucros; produtividade; emprego

Código jel : J33

\section{WORKERS PARTICIPATION IN PROFITS AND FIRM PERFORMANCE:}

LESSONS FROM THE INTERNATIONAL EXPERIENCE

ABSTRACT Having reviewed a large body of international empirical evidence on the impacts of schema of workers participation in profits and firm performance, it is shown that the less-studied Brazilian experience provides casual evidence that those schema are able to improve firms performance and labor relations inside the firm. Drawing upon evidence from some countries's successful experience, policy recommendations are advanced with respect to the Brazilian case.

Key words: profit sharing; productivity; employment

\footnotetext{
* Artigo recebido em 22 de julho de 2005 e aprovado para publicação em 31 de março de 2006. Cabem agradecimentos — acompanhados das isenções de praxe — a dois pareceristas anônimos e a Cássio Calvete por valiosos comentários e sugestões.

** Graduanda em Economia na FEA-USP e assistente de pesquisa da FIPE-USP, e-mail: daniela_gmc@ yahoo.com.br

*** Professor do Departamento de Economia na FEA-USP, e-mail: giltadeu@usp.br
} 


\section{INTRODUÇÃO}

A participação dos trabalhadores nos lucros e resultados (PLR) das empresas é uma modalidade que vem crescendo nos últimos anos, especialmente nos países de economia mais avançada, como Japão, Estados Unidos, Inglaterra, Alemanha e França (neste último, as firmas que empregam mais de 50 trabalhadores são obrigadas a oferecer mecanismos de participação nos lucros aos funcionários). Os principais argumentos em favor deste sistema são a noção de que ele criaria incentivos que moveriam a economia para o pleno emprego, como sugere Weitzman (1984), e a crença de que ele é capaz de promover o aumento da produtividade na firma. Além disso, esquemas de participação nos lucros (PL) tenderiam a aumentar a estabilidade do trabalhador na empresa e seu comprometimento com os resultados daquela, o que estimularia mais investimentos em capital humano firma-específico, tanto por parte da firma como da parte do próprio funcionário, reforçando o efeito de incremento na produtividade.

Existem diferentes meios pelos quais os trabalhadores podem participar financeiramente no desempenho das empresas em que trabalham. O mais comum é a participação nos lucros (PL), que implica o recebimento de uma proporção da renda relacionada aos lucros da firma. Todos ou a maior parte dos trabalhadores devem ser abrangidos pelo sistema para que a firma possa ser considerada como operadora de um esquema de participação nos lucros. Não há um consenso sobre o papel do rendimento provindo da participação dos lucros entre os autores que já trataram desta questão; algumas abordagens sugerem que o componente baseado no lucro pode ser um substituto para os salários básicos, enquanto outros acreditam que a participação nos lucros só pode ser considerada genuinamente como tal se ela significar um pagamento adicional ao salário-base. Há ainda uma segunda modalidade de participação dos trabalhadores nas empresas, que é a possibilidade de aquisição de cotas acionárias das firmas em que trabalham, fazendo com que, em alguma medida, os trabalhadores possam interferir em decisões futuras sobre o processo produtivo e as relações de trabalho. ${ }^{1}$ Uma terceira forma de participação é a divisão de ganhos, que é diferenciada da participação nos lucros pelo fato de que ela pode variar de maneira independente do desempenho dos empregados. Esta forma de participação pode estar baseada em redução de custos, aumentos de produtividade ou 
qualquer outra meta previamente estabelecida. Por fim, existe ainda a opção de o trabalhador ser compensado com um quantia fixa (lump sum), o caso mais comum nos EUA.

Uma série de estudos empíricos realizados ao longo das últimas décadas foi analisada para a elaboração deste trabalho, buscando sintetizar os resultados já encontrados para os efeitos dos esquemas de participação dos trabalhadores nos lucros e resultados das empresas. Apesar de algumas evidências favoráveis aos efeitos da PLR sobre a produtividade, a rentabilidade e o emprego, não há um consenso entre os autores que se propuseram a examinar esses efeitos. As diferenças de resultados podem ser explicadas tanto pelas diferenças qualitativas como quantitativas das amostras, por diferenças de abordagens, diferenças regionais e mesmo temporais, dado que as pesquisas não estão concentradas em uma região de desenvolvimento e estruturas homogêneas e tampouco em um espaço de tempo rigidamente delimitado. O presente artigo concentrar-se-á nos resultados internacionais para os casos "legítimos" de PLR, fazendo referência aos demais esquemas de participação somente na medida em que servirem para elucidar melhor o caso em foco.

Este artigo está dividido da seguinte forma: na seção 1 é apresentado um panorama geral dos resultados de diversos estudos realizados sobre os efeitos dos esquemas de participação em diferentes parâmetros considerados, com relatos sucintos desses estudos para alguns autores selecionados. $\mathrm{Na}$ seção 2 tratamos da experiência brasileira, ainda pouco estudada, mas que oferece indícios que vão ao encontro da opinião de que esquemas de PLR podem melhorar os indicadores das empresas que os adotam e as relações no ambiente de trabalho. Na última seção será apresentada a conclusão do trabalho, onde se buscará apontar algumas possíveis direções para onde o caso brasileiro deve caminhar, com base em experiências de sucesso realizadas em outros países. O papel de políticas públicas de incentivo aos esquemas de participação também será brevemente abordado nessa seção.

\section{PARTICIPAÇÃO DOS TRABALHADORES NOS LUCROS DAS EMPRESAS: VISÃO GERAL}

A PLR permite aos trabalhadores se beneficiarem do êxito das empresas em que trabalham, e essa perspectiva de obtenção de benefícios extras parece motivar uma maior dedicação desses trabalhadores a suas atividades, au- 
mentando seu comprometimento com os resultados da empresa. Sob tais circunstâncias deveriam ser esperados, portanto, reduções no número de faltas, na rotatividade dos trabalhadores e nas tensões internas da firma, maior investimento em capital humano firma-específico e melhorias na organização do trabalho. $\mathrm{O}$ aumento na eficiência e na produtividade, levando a uma maior competitividade e um melhor desempenho, parecem, ao menos na teoria, justificativas consistentes em favor da adoção da PLR. Ainda de acordo com a teoria, o número de trabalhadores envolvidos no esquema de PLR deveria influenciar a reação daqueles aos esquemas, funcionando como desestímulo à motivação individual, na medida em que cresce o número de participantes. Isso ocorreria porque, quanto maior o número de envolvidos, mais explícito passa a ser o problema do "carona". Assumindo uma empresa com um número $\mathrm{N}$ de trabalhadores, qualquer esforço extra de um trabalhador individual resultaria na apropriação de apenas $1 / \mathrm{N}$ do acréscimo de lucro produzido. Assim, quanto maior o número de empregados envolvidos, menor o estímulo para a produção de esforço extra. Entretanto, o uso deste argumento negligencia a interação que ocorre dentro dos grupos. A partir do momento em que se instaura um esquema de incentivo coletivo, em que o desempenho de cada trabalhador afeta o rendimento de todos, cria-se um incentivo à cooperação de modo a maximizar o desempenho do grupo como um todo (FitzRoy e Kraft, 1986).

Muitos autores enfatizam ainda a importância de outros fatores organizacionais para o sucesso da participação nos lucros. Bell e Hanson (1987), por exemplo, acreditam que a adoção da PLR é geralmente uma conseqüência de um estilo mais participativo, proposto pelos principais gerentes da firma que acreditam que a adoção da PLR é uma das chaves para provocar o comprometimento dos funcionários com o sucesso da firma, o que traria resultados melhores tanto para acionistas como para gerentes e empregados. Levine e Tyson (1990) acreditam que PL e participação devem acontecer simultaneamente para que esses esquemas funcionem com sucesso, pois onde há PL, o rendimento dos trabalhadores depende das decisões das firmas, e os trabalhadores desejarão ter voz ativa nas decisões tomadas. Em pesquisa recente sobre a relação entre rentabilidade e PL, Kim (1998) encontrou evidências formais sobre a interação entre envolvimento dos trabalhadores e PL. Kruse (1993), no entanto, ao tentar determinar a interação entre PL e outras políticas pessoais (tais como enriquecimento do trabalho, envolvi- 
mento dos trabalhadores e segurança no trabalho), não encontrou muitas evidências de que tais políticas interagem com a PL.

A introdução de esquemas de participação dos trabalhadores nas empresas - seja através da participação nos lucros, da participação acionária ou ainda da participação nos ganhos - é uma sugestão de alguns economistas para melhorar tanto a situação das firmas como a de seus funcionários. A da firma, pois esta poderia contar com funcionários mais motivados e empenhados em aumentar a produtividade da empresa, fator importante em um ambiente concorrencial cada vez mais acirrado. Além disso, esse maior comprometimento do empregado com sua empresa facilitaria a decisão de realização de investimentos específicos, o que acentuaria ainda mais a característica do esquema de incentivador da produtividade.

Para os trabalhadores, os esquemas de participação significam uma maior garantia de emprego, especialmente nos períodos de crise, quando o ajuste se daria pela redução do nível da remuneração, e não pelo corte de empregos. Ainda, em períodos de expansão do nível de atividade, o rendimento auferido pela participação nos lucros pode significar um incremento considerável na renda do trabalhador. Apesar, no entanto, das possibilidades levantadas pela teoria, as evidências empíricas não sugerem com tanta convicção que tais resultados são de fato alcançados. Na maioria dos casos, são tímidas as evidências de que os esquemas de participação podem ser responsabilizados por melhores resultados nas firmas que os adotaram. Para ilustrar este ponto, alguns estudos e seus resultados serão apresentados com maior grau de detalhamento no subitem a seguir.

\subsection{Evidência empírica}

Vários autores internacionais já se interessaram pelo estudo dos efeitos da adoção de esquemas de participação em fatores como produtividade, emprego, salários, investimentos, entre outros, e os resultados de uma amostra representativa desses trabalhos serão apresentados nesta seção. A relação mais comumente abordada pelos autores é aquela existente entre a adoção dos esquemas de PL e a produtividade. Isso porque, de acordo com eles, os efeitos de um sobre o outro parecem diretos, pois os trabalhadores percebem, com a instituição da participação nos lucros, um incentivo maior para aumentarem seus esforços, já que, a partir de então, parte do lucro obtido com esse esforço extra passa a ser um componente de sua própria renda. 
O grande crescimento na incidência de programas da PL em países da OECD nas últimas décadas, mesmo naqueles que não haviam introduzido legislação de incentivo e vantagens fiscais, motivou o trabalho de Estrin, Pérotin, Robinson e Wilson (1997). Os autores acreditam que há duas características que distinguem a PL de outros esquemas de participação: (i) é uma forma de pagamento variável e (ii) é um esquema de incentivo de grupo relacionado ao desempenho da empresa como um todo. Sobre o primeiro ponto, os autores esclarecem que a PL não deve incluir bônus fixos ou outras distribuições que não estejam relacionadas ao desempenho da firma. Na prática, a PL estaria freqüentemente combinada com participação acionária dos trabalhadores e poderia estar associada com outras formas de participação financeira e com níveis variados de informação compartilhada e participação na tomada de decisões.

Os países analisados foram categorizados em três grupos, conforme a incidência de esquemas de PL: países com alta incidência (em que os esquemas de PL cobriam ao menos 15\% dos trabalhadores), como França e Japão; países com incidência relativamente alta (ao menos 5\% dos trabalhadores), como por exemplo Reino Unido, Estados Unidos, Alemanha e Canadá; e, por fim, países com baixa incidência, como Austrália e Bélgica. Os autores acreditam que incentivos coletivos não têm o mesmo efeito que os incentivos individuais sobre o esforço dos trabalhadores. Tal afirmação é baseada nos conceitos defendidos por FitzRoy e Kraft (1986, 1987), que serão mais bem explicados adiante. Em relação à capacitação produtiva da força de trabalho e sua predisposição a continuar na firma, os autores acreditam que, se a PL aumentar a conscientização do grupo e auxiliar na resolução de conflitos, então ela pode reduzir a rotatividade e aumentar os investimentos em capital humano firma-específico. Finalmente, defendem que a eficiência organizacional deve ser maior em firmas que operam esquemas de participação - com ou sem PL. Resultados empíricos apresentados pelos autores sugerem que as firmas que haviam introduzido esquemas de PL eram mais eficientes, no sentido de que produziam mais para um dado nível de fatores de produção.

Ao analisarem os efeitos da PL sobre a produtividade e o emprego na França — país em que empresas com mais de 50 funcionários são obrigadas a oferecer algum tipo de esquema de participação aos trabalhadores - Cahuc e 
Dormont (1997) encontraram evidências de efeitos positivos daquela sobre a produtividade, porém, no que diz respeito ao emprego, os autores acreditam que os efeitos podem ser ambíguos. Na França, o salário-base não pode ser reduzido ou substituído pelos rendimentos advindos da PL e, desse modo, os autores sugerem que, a não ser que esse custo extra seja compensado pelo aumento da produtividade, os empregadores não teriam motivo para sustentar a PL, especialmente nos casos de adoção voluntária - segundo Estrin, Pérotin, Robinson e Wilson (1997), em 1992, 10,4\% dos trabalhadores cobertos pelo esquema de PL eram de firmas que adotaram voluntariamente a PL. Ainda de acordo com os resultados dessa pesquisa, firmas que operam com PL têm um desempenho melhor em relação à produtividade do trabalho e à lucratividade, e sua taxa de emprego também cresce mais. Os autores destacam, no entanto, que tais efeitos não são necessariamente devidos à adoção da PL, e podem estar associados a outros fatores negligenciados na pesquisa.

A popularização dos esquemas de pagamentos relacionados ao lucro e a posição oficial do governo do Reino Unido, que passou a oferecer mudanças na tributação de firmas que adotavam esquemas de PL, motivaram Blanchflower e Oswald (1988) a avaliar os efeitos de tais esquemas nas relações industriais, na produtividade das empresas e no crescimento do emprego no país. Os autores detectaram um forte crescimento no número de trabalhadores cobertos por esquemas de PL a partir do fim dos anos 70, quando da introdução dos incentivos fiscais. Os autores não encontraram, no entanto, nenhuma correlação muito forte entre a existência de programas de participação e o desempenho financeiro demonstrado pelos estabelecimentos. As principais influências citadas como determinantes para a lucratividade daquelas empresas que tinham declarado desempenho "acima da média" em relação aos concorrentes foram antes fatores como o tamanho do estabelecimento (quanto maior, maior a probabilidade de declarar desempenho acima da média), o aumento no valor das vendas dos principais produtos e serviços no período compreendido pela pesquisa, a proporção de variação nos salários (quanto menor, maior a probabilidade de desempenho acima da média) e, finalmente, a existência ou não de organizações trabalhistas reconhecidas dentro do estabelecimento (sua presença reduzia a probabilidade). A PL não foi lembrada como fator determinante para a melhora no 
desempenho pelos respondentes. Blanchflower e Oswald (1988) também encontraram uma pequena indicação de correlação entre crescimento de emprego e a existência de esquemas de participação. No que diz respeito à qualidade das relações industriais, encontrou-se um padrão muito similar tanto para as empresas que adotavam como para aquelas que não adotavam a PL. Para os autores, ainda não havia claras evidências empíricas, fossem a favor ou contra a política de incentivo aos pagamentos relacionados à participação.

Resultados um pouco mais otimistas foram encontrados por Cable e Wilson (1989) que, baseados em dados colhidos junto a algumas empresas de engenharia do Reino Unido, constataram que aquelas que tinham esquemas de PL apresentavam índices de produtividade mais elevados, entre 3\% e $8 \%$ acima das demais. No entanto, esses esquemas haviam sido introduzidos, com freqüência, como parte de um pacote envolvendo nova tecnologia, e haviam sido negociados diretamente com a força de trabalho. Isso deveria significar que essas firmas apresentavam melhor progressividade técnica e maior propensão a investir, assim, os ganhos de produtividade observados poderiam ser antes associados à qualidade de sua gerência e melhor utilização de equipamentos mais novos e mais avançados tecnicamente, e não à PL. Na extensão deste trabalho, os autores apresentaram resultados comparativos entre as empresas do Reino Unido e uma amostra de indústrias metalúrgicas do leste da Alemanha (Cable e Wilson, 1990). Foram encontradas diferenças substanciais entre os resultados dos dois países em relação à magnitude do efeito sobre a produtividade total. Enquanto no caso britânico os diferenciais de produção previstos estavam entre 3,1\% e 8,2\%, no leste da Alemanha eles eram ampliados para valores entre $20,1 \%$ e $30,1 \%$. Em conformidade com o primeiro estudo, os autores avaliaram que importantes interações entre PL e outros aspectos da organização das firmas e sua operação afetavam o desempenho das empresas. As firmas com PL também apresentavam maior grau de sindicalização, maior propensão a investir e maior progressividade técnica.

Wadhwani e Wall (1990), utilizando dados no nível micro para empresas manufatureiras também no Reino Unido, encontraram evidências de incremento na produtividade após a adoção de esquemas de PL, porém, não acreditam que tais evidências permitam estabelecer uma relação necessaria- 
mente causal entre os fatos. As firmas que adotaram esse esquema - firmas grandes, em média, com mais de 10 mil empregados — também apresentaram declínio ligeiramente menor no emprego e volatilidade relativamente menor de mudanças de emprego. Essas diferenças, porém, foram bastante tímidas. Em termos salariais, as empresas com PL apresentavam um nível de remuneração também ligeiramente mais elevado, enquanto a taxa de aumento no salário-base era um pouco menor. $\mathrm{O}$ aumento na produtividade, mesmo em empresas de grande porte, contesta o argumento de que quanto maior o número de empregados abrangidos pelo esquema, menor o incentivo do trabalhador individual para produzir maior esforço, por causa do risco do efeito carona. Outros fatores parecem merecer atenção neste caso, como o comprometimento moral de cada indivíduo com o grupo para alcançar melhores resultados. Os autores ainda constataram que, ao invés de levar a uma redução na pressão salarial, a introdução da PL na verdade aumenta a remuneração total. Neste ponto sugerem que, ao invés de fornecer um remédio para o problema da inflação, a PL pode mesmo ser inflacionária, com efeitos que tendem a reduzir o emprego. Apesar desta observação, os autores não se posicionam de maneira mais contundente sobre os efeitos da PL no nível de emprego.

Em relação às implicações dos programas de PL sobre a inflação, Wadhwani (1987) testou o argumento defendido por Weitzman (1984) de que a PL pode ser um remédio para o fenômeno da estagflação. Wadhwani (1987) usa o exemplo do Japão, país em que a PL é largamente adotada, e cujo desempenho econômico no pós-guerra foi superior ao dos demais países de nível semelhante de desenvolvimento. A principal razão apresentada para o fato de uma economia que utiliza esquemas de PL ser mais resistente à estagflação é que suas firmas operariam em um regime de trabalho com excesso de demanda positivo. Isso implicaria que choques de demanda agregada não tivessem efeito - ou tivessem efeito reduzido - na produção, e que, para uma postura política dada, mudanças nos preços de importação ou pressões salariais não teriam efeitos na inflação de preços. O autor, no entanto, não encontrou nenhuma evidência em favor de tais proposições ao analisar o caso japonês. Ele acredita, porém, que a PL pode ter outros efeitos benéficos, como servir de estímulo à produtividade. Segundo o autor, outras razões podem explicar o sucesso japonês, como fatores culturais ou maior 
flexibilidade salarial, por exemplo. Além do mais, avalia que, em relação à inflação, o desempenho do Japão não foi significativamente melhor do que o de qualquer outro país industrial.

Ainda em relação ao Japão, Kato e Morishima (2003) avaliaram a disseminação e os efeitos dos esquemas de PL nas firmas japonesas. As principais constatações dos autores foram que, em primeiro lugar, ao contrário do que supõe a noção popular de uma adesão quase universal das empresas japonesas, apenas 1 em cada 4 usavam programas de PLR. ${ }^{2}$ Além disso, os programas de PLR mostraram-se mais populares entre as empresas menores, e sem a presença de sindicatos. Isso porque, nas firmas menores, seria mais fácil o monitoramento dos colegas. Os programas de participação nos lucros geralmente eram compartilhados por todos os trabalhadores das empresas. Quase todos os programas PLR japoneses analisados pelos autores são do tipo "cash plans", ao contrário do caso norte-americano, onde os "deferred plans” são mais populares. ${ }^{3}$ Aproximadamente metade das firmas não estabelece fórmulas pelas quais a contribuição é ligada aos lucros. A fórmula mais popular usada por empresas que adotam programas de PLR é uma porcentagem específica do lucro excedente a uma meta preestabelecida.

No que concerne ao desestímulo que os trabalhadores teriam em aceitar a adoção de incentivos coletivos, conforme crescesse o número de trabalhadores envolvidos, FitzRoy e Kraft (1986) defendem que os incentivos coletivos podem aumentar a motivação e a produtividade, ainda que em grandes organizações. Para sustentar seus argumentos, os autores analisaram uma amostra de empresas de porte médio no setor metalúrgico, no leste da Alemanha. De acordo com os resultados, a PL e a participação acionária dos empregados geravam efeitos positivos robustos na lucratividade das empresas. Para os autores, a principal falha no argumento do efeito carona contra os incentivos coletivos é que a interação dentro do grupo é negligenciada. Incentivos coletivos implicam que uma ação individual impõe externalidades aos demais membros do grupo, e que, dado que a interação não é difícil graças à tecnologia e à organização do trabalho, então a resposta racional aos incentivos coletivos é a cooperação. Especialmente em situações de trabalho cujo esforço individual é difícil de monitorar e recompensar, é possível que o processo de produção se torne mesmo mais eficiente, graças ao estímulo à cooperação entre os trabalhadores. Os resultados empíricos desse estudo 
mostram ainda que o retorno residual do capital dos proprietários aumenta com a quantidade de PL e com a participação dos trabalhadores.

FitzRoy e Kraft (1986) defendem ainda que a adoção de esquemas de PL beneficia as relações de emprego de longo prazo e estas, por sua vez, incentivam maiores investimentos específicos por parte das firmas. Para aprofundar a questão sobre a cooperação, mesmo em grandes empresas, os autores analisaram em trabalho posterior (FitzRoy e Kraft 1987) a relação entre cooperação, produtividade e PL. Os autores lembram que cooperação, comunicação e capital humano tornaram-se, de modo crescente, importantes fatores de produção, que são menos facilmente monitorados e motivados com os incentivos individuais tradicionais. Conforme os resultados revelados nesse trabalho, a PL era capaz de aumentar a produtividade, desde que a organização do trabalho facilitasse a interação entre os trabalhadores. Porém, se os trabalhadores acreditassem que a maior parte dos ganhos oriundos do aumento da produtividade seria apropriada pelos proprietários ou gerentes, a melhor estratégia para o grupo seria manter seus benefícios não-pecuniários, limitando seu esforço. A alternativa para este problema seria o oferecimento, através de um contrato, de uma parte nos lucros capaz de garantir um retorno marginal substancial para motivar o esforço e a eficiência. Enquanto um excedente fixo oferece um incentivo individual reduzido, a não ser para equipes pequenas, um esquema de participação ou de recompensa ao grupo gera externalidades positivas de esforço e cooperação.

Utilizando-se de uma abordagem um pouco diferente, Bhargava (1994) estudou a relação dinâmica entre a PL e a lucratividade em uma amostra de firmas do Reino Unido. Para o autor, um dos indicadores-chave do desempenho financeiro e do sucesso de uma firma é a taxa de retorno do capital, que não foi adequadamente explorada na literatura sobre o tema. Tanto os trabalhadores como os empregadores estariam igualmente interessados em ver a rentabilidade da firma em uma tendência crescente, especialmente se a firma adotar um plano de PL, dado que salários maiores são conseqüência de lucros maiores, em função da distribuição da renda. Bhargava (1994) acredita que o principal mecanismo pelo qual a PL pode elevar a lucratividade é aumentando a eficiência com a qual o trabalho é utilizado no processo produtivo. Neste sentido, a participação financeira dos trabalhadores por meio de esquemas como a PL promoveria motivação e mais esforço por 
parte deles. O aumento de esforço por unidade de pagamento vai incrementar os lucros e também o retorno do capital na firma. Os resultados do estudo indicam que a introdução da PL teve efeitos positivos e, na maioria dos casos, significantes na lucratividade.

Para Kruse (1992), a PL pode melhorar o desempenho da companhia sob três hipóteses: (i) aumento do esforço do trabalhador; (ii) aumento da capacitação da mão-de-obra; e (iii) melhora do fluxo de informação dentro da organização. Em relação ao aumento do esforço por trabalhador, Kruse (1992) considera o problema do efeito carona, mas acredita que ele é consistente apenas para o caso em que são oferecidos incentivos individuais aos trabalhadores, e não incentivos coletivos. Sob um sistema de incentivos individuais, os trabalhadores podem se envolver em problemas de rivalidade com outros trabalhadores, o que incorreria em custos para a firma. Sob um esquema de incentivos coletivos, porém, os empregados estão aptos para monitorar uns aos outros de maneira mais fácil e eficiente ("monitoramento horizontal”) do que o empregador e, como um grupo, podem internalizar as externalidades positivas das decisões individuais de cooperar em tarefas interdependentes. A segunda hipótese deve-se à idéia de que a PL reduz a rotatividade dos trabalhadores, o que encoraja investimento adicional em capital humano firma-específico. A terceira hipótese sustenta-se pelo fato de que a eficiência geral da organização será aumentada pela PL. Os trabalhadores estariam mais predispostos a compartilhar informações técnicas com a gerência, o que poderia melhorar a operação do processo produtivo. Além disso, os trabalhadores também poderiam se mostrar mais dispostos a aceitar mudanças tecnológicas que aumentem os lucros.

Os resultados sobre a influência dos esquemas de PL na produtividade, com base em dados de empresas norte-americanas, indicaram que a adoção da PL estava associada a um aumento na produtividade que variava entre $2,8 \%$ e $3,5 \%$ para companhias manufatureiras e entre $2,5 \%$ e $4,2 \%$ para as não-manufatureiras. Quando a PL era medida como proporção dos empregados abrangidos, os efeitos estimados aumentavam para 7,9\% a 8,9\% para as manufatureiras e $10,3 \%$ a $11 \%$ para as não-manufatureiras (para planos que cobriam $100 \%$ dos trabalhadores). Kruse (1992) lembra que, ainda que a PL aumente a produtividade em apenas $1 \%$, economicamente esse efeito é significativo. Assumindo uma elasticidade de produção do capital de 0,25 , um 
aumento de produtividade de $1 \%$ seria equivalente a um aumento no estoque de capital de $4 \%$. Os efeitos encontrados para os planos de participação acionária não apresentaram efeitos tão consistentes como no caso da PL.

Outras evidências dos Estados Unidos, reveladas por diferentes estudos, sugerem que há uma relação positiva entre programas de participação e o desempenho das empresas que os adotaram, ainda que tais evidências não sejam estatisticamente significantes. Kruse e Blasi ${ }^{4}$ (1997), que revisaram os resultados de 11 trabalhos sobre o desempenho de empresas que adotaram esquemas de participação em relação a suas concorrentes, que não haviam adotado tais esquemas, confirmam a relação positiva entre participação e produtividade. Quarrey e Rosen ${ }^{5}$ (1997) também associaram os esquemas ao aumento das vendas e do desempenho dos trabalhadores. A média anual de crescimento do emprego nas empresas com participação em relação a suas concorrentes era 3,8\% maior. Os planos de participação nos Estados Unidos começaram a ser introduzidos nos anos 50, e estima-se que atualmente cerca de $6,4 \%$ dos trabalhadores no setor privado do país participem de esquemas de participação.

Bell e Neumark (1993) decidiram estudar, também para o caso norteamericano, os efeitos dos planos de PL e lump sum $(L S)^{6}$ no crescimento do emprego e dos custos do trabalho para os setores sindicalizados. A motivação dos autores foi o surgimento concomitante de moderação salarial e o advento dos planos de PL e LS. Os autores acreditavam que poderia haver uma ligação causal entre o crescimento desses planos e as tendências apresentadas pelos salários agregados. Um segundo efeito que os autores consideravam como uma possível conseqüência da introdução dos planos era o aumento da estabilidade do mercado de trabalho. Os resultados do estudo apontaram para um diferencial no crescimento dos custos do trabalho entre as firmas que adotavam e as que não adotavam esquemas de participação nos lucros. As firmas que negociavam esquemas de PL apresentavam crescimento nos custos do trabalho menor do que aquelas que não adotavam o plano, além de maior crescimento no emprego e na estabilidade. Por outro lado, firmas com LS não apresentavam menores custos de trabalho ou aumento no emprego, e ainda aumentavam a instabilidade no emprego. Como os resultados para os esquemas de PL tendiam a corroborar as previsões da teoria em relação a pagamentos condicionados ao desempenho, ao contrá- 
rio do que ocorreu com os esquemas de LS, os autores concluíram que este último não representa um esquema legítimo de pagamento condicionado ao desempenho.

Os efeitos da introdução de esquemas de PL na estabilidade do emprego também foram alvo de estudo de Azfar e Danninger (2001), que analisaram ainda as conseqüências da PL sobre os investimentos e os salários em empresas norte-americanas. Os autores defendem que a PL aumenta a produtividade por um canal diferente do tradicionalmente abordado - maior esforço dos trabalhadores; para os autores, é por meio da redução da rotatividade que a PL gera efeitos positivos sobre a produtividade. A partir do momento em que reduz a rotatividade, a PL aumenta a estabilidade esperada no emprego e, portanto, aumenta o período de amortização para investimentos em capital humano. Em tais condições, seria ótimo tanto para empregados como para empregadores aumentar seus investimentos em capital humano específico. A alta taxa de rotatividade no mercado de trabalho seria a responsável pela redução nos investimentos em treinamentos específicos nas firmas, com efeitos no crescimento da produtividade potencialmente grandes. A hipótese testada pelos autores é a de que a PL pode neutralizar essa tendência, sobretudo porque tornaria os salários mais flexíveis, dado que ela automaticamente reduziria os custos do trabalho em um mercado em condições adversas.

A estrutura de salário inflexível nessas condições aumentaria a taxa de rotatividade e, portanto, limitaria o escopo de investimento em capital humano específico para a firma. A PL tenderia a atenuar esses efeitos, proporcionando maior estabilidade no trabalho e criando, conseqüentemente, melhores condições para a realização de investimentos estimuladores de produtividade. Os resultados do estudo indicam que os trabalhadores participantes de planos de PL eram na média mais capacitados, trabalhavam em plantas maiores e tinham maior experiência de trabalho. A rotatividade dos trabalhadores em empresas que adotavam a PL era cerca de $40 \%$ menor, considerando-se tanto casos de troca de emprego como demissões. As medidas de treinamento, incidência e duração, eram ambas maiores para trabalhadores sob esquemas de PL (entre 60\% e 80\% mais elevadas). Essa descoberta poderia sustentar a hipótese dos autores de que uma maior estabilidade no emprego aumenta os investimentos em treinamentos firma-específicos. Por 
último, se os trabalhadores com PL ainda investem em treinamentos específicos adicionais, então isso deveria ser refletido em um crescimento salarial mais elevado. Na verdade, Azfar e Danninger (2001) concluíram que a PL adicionava $3 \%$ ao crescimento salarial anual.

Chelius e Smith (1990) também abordaram a questão do diferencial na estabilidade do emprego entre firmas que adotam e as que não adotam a PL. Os autores testaram a hipótese de que trabalhadores cujo "pacote de remuneração" continha o componente PL estavam menos suscetíveis de serem demitidos em caso de um choque negativo de demanda do que os trabalhadores que tinham um salário fixo baseado no número de horas trabalhadas. Para os autores, o uso do salário nominal fixo é acompanhado de um custo social elevado, que é o desemprego persistente causado pelo ajuste do nível de emprego, em vez dos salários, aos choques negativos de demanda. Quando as firmas optam por usar um sistema híbrido de remuneração (salários baseados nas horas trabalhadas e PL) no nível de emprego maximizador dos lucros, o produto marginal do trabalho deve se igualar ao salário de mercado. A firma vai desejar contratar um trabalhador adicional no curto prazo se a renda do produto marginal do trabalho exceder o custo marginal; uma firma que paga seus trabalhadores na base de PL vai entender que seus lucros podem aumentar se ela contratar um trabalhador adicional, desde que a renda do produto marginal exceda o salário garantido.

No caso de um choque de demanda negativo, em que a renda do produto marginal do trabalho cai abaixo do salário de mercado, a solução para a firma que opera com salários fixos é demitir trabalhadores; já na firma que utiliza esquemas de PL, não haverá incentivos para a demissão de funcionários a menos que o produto marginal do trabalho caia abaixo do salário garantido. Ainda que a remuneração dos trabalhadores caia em períodos de choques negativos, demissões não resultam necessariamente dessas crises. De acordo com os resultados da análise de dados de duas amostras de empresas norte-americanas, empresas que sofreram declínio das vendas no ano de 1987 e que adotavam PL tiveram redução no emprego de cerca de $8 \%$, enquanto as que não adotavam tiveram redução de cerca de $10 \%$. Dos trabalhadores que responderam à pesquisa e trabalhavam em empresas com PL, apenas 4\% haviam sido demitidos nos últimos 12 meses; para aqueles que trabalhavam em empresas sem PL, esse índice foi de 7\%. No longo pra- 
zo, empresas com e sem PL fizeram adições similares em termos de emprego. Este resultado sugere que, se há efeitos da PL no emprego, eles se revelam especialmente em períodos de crise.

Ainda na esteira dos autores que relacionaram esquemas de PL com taxas menores de desemprego, Fung (1989) examinou algumas propriedades da PL como uma alternativa possível para mitigar as altas taxas de desemprego européias. O autor utilizou três critérios para avaliar a PL como uma política para melhorar o desempenho econômico europeu: a redução do salário real, a expansão dos lucros das firmas e a restrição da demanda salarial dado um estímulo expansionista da demanda. Na análise dos efeitos da PL no comportamento da fixação salarial da união trabalhista européia, Fung (1989) concluiu que, em competição perfeita ou monopólio, o salário real cai com a PL. Tal resultado era produzido, segundo o autor, pois a preocupação da união em relação à PL reduziria a taxa de salário para aumentar a função lucro. Logo, com a PL, emprego e demanda expandiriam, enquanto o nível de preços cai. Em um oligopólio Cournot-Nash, a PL pode, teoricamente, aumentar o salário real, de acordo com Fung (1989). Esta possibilidade surge porque, com a PL, a união tem incentivos para aumentar o lucro das firmas. Os lucros podem crescer com oligopolistas se cada firma reduzir sua produção, então a produção total fica perto de um resultado de monopólio. Essa redução, por sua vez, pode ser alcançada se os salários aumentarem. Entretanto, os efeitos no salário real foram considerados ambíguos.

No que diz respeito à relação entre PL e taxa de lucro, Fung (1989) sugere que esse plano expande os lucros, além de distribuí-los ao trabalho. A soma das rendas das uniões e os lucros das firmas crescem com a PL. Portanto, ao menos potencialmente, tanto a união como a firma podem sair ganhando. $\mathrm{O}$ autor acredita que os elaboradores de política econômica na Europa se recusam a adotar uma política de demanda agregada expansionista por receio de que esta pudesse conduzir a uma inflação explosiva. No entanto, ao comparar a resposta do salário real a uma política de demanda agregada expansionista em uma economia com PL e outra sem o esquema, ele conclui que, se a demanda do produto e as funções-custo forem lineares, então a propensão marginal da união para aumentar seus salários é menor onde há PL.

Gottfries e Sjöström (1995) também acreditam que a PL pode ser usada para atingir o nível eficiente de emprego, além de preservar uma divisão óti- 
ma de riscos entre as partes. A adoção da PL é indicada pelos autores como um meio de evitar as trocas de emprego ineficientes, ao mesmo tempo em que estabiliza a renda dos trabalhadores. Os autores acreditam que, tornando o salário uma função convenientemente crescente do lucro, é possível estabilizar os salários entre situações de crise e prosperidade. Um modelo ótimo de PL seria aquele em que os trabalhadores teriam renda constante entre duas situações. Os autores não acreditam que a maior vantagem da PL seja o fato de ela tornar os salários mais flexíveis; ao contrário, para eles, eficiência requer renda estável para os trabalhadores e, ao mesmo tempo, a criação de custo marginal do trabalho baixo para as firmas, como modo de obter um nível eficiente de emprego. Um esquema de PL ótimo alcançaria exatamente tais objetivos. Os autores defendem que a adoção da PL é útil apenas sob algumas condições: (i) os trabalhadores devem ter poder de barganha, de modo que seus salários excedam o salário de reserva; (ii) os trabalhadores empregados sofrem com a ameaça de demissões; (iii) o seguro-desemprego é ineficiente; (iv) a demanda ou a produtividade são incertos e os trabalhadores são avessos ao risco; e (v) os lucros são observáveis e bastante correlacionados com choques no produto marginal do trabalho. Cada uma dessas condições é necessária para o modelo de PL admitido no trabalho. Os autores argumentam ainda que existe uma motivação real para a adoção da PL somente sob a presença de incerteza. Sob certeza, dizem, não haveria motivo para que o nível de emprego não pudesse ser especificado no contrato, eliminando a necessidade da PL. Ainda que essa especificação não fosse possível, um contrato que relacionasse o salário ao emprego, e não ao lucro, seria suficiente para se alcançar a eficiência em um ambiente sem incerteza.

Um estudo recente sobre os efeitos da participação acionária dos trabalhadores em indústrias pesadas chinesas foi conduzido por Tseo, Sheng, Peng-zhu e Lihai (2004). As empresas estatais dominavam esse setor, que também era caracterizado por uma extrema ineficiência (as perdas eram causadas por desperdício de materiais ou por roubos por parte dos trabalhadores, dívidas elevadas e falta de autonomia gerencial em razão de restrições burocráticas) e desafiavam a continuidade do desenvolvimento de várias províncias. Fatores externos como as novas forças competitivas do mercado aberto reduziam a margem de lucros e, por conseqüência, o nível 
de emprego. Internamente, começaram a surgir pressões orçamentárias para economia de recursos pela redução de salários e benefícios. Como tentativa de solucionar o problema da eficiência, algumas empresas começaram a oferecer a opção de compra de participação acionária aos trabalhadores, um programa que se espalhou rapidamente. Na maioria das empresas em que trabalhadores passaram a ter participações foram notados ganhos de eficiência e rentabilidade. Em alguns casos, em que a força de trabalho teve a chance de adquirir 100\% da firma, os lucros aumentaram mais de 100\% em um período de quatro meses. Os ganhos de produtividade, entretanto, tendiam a se dissipar depois de dois anos. Ao contrário das expectativas, mesmo quando eram os gerentes que compravam parte ou a totalidade das empresas, ainda se notavam efeitos positivos sobre o desempenho da empresa. O mesmo não se verificava, no entanto, quando os trabalhadores conquistavam direito à participação na governança das empresas; neste caso, os efeitos eram negativos. Apesar de a pesquisa sugerir que o desempenho das empresas regredia depois de alguns anos, os autores advertem que devem ser levados em consideração o período e os efeitos de crises regionais e globais ocorridas no fim dos anos 90.

Outro estudo também recente foi elaborado por Cahill (2000), que analisou a introdução de esquemas de participação financeira sobre o resultado das empresas na Irlanda. O estudo analisou os resultados de duas pesquisas conduzidas no país. Uma delas avaliou que 11\% dos estabelecimentos irlandeses (esta pesquisa avaliou a população total de estabelecimentos no país) tinham esquemas de PL e outros 11\%, esquemas de participação acionária. Como poderia haver casos de coincidência de ambos os planos nos estabelecimentos, conclui-se que no máximo 22\% tinham algum esquema de participação. A segunda pesquisa foi baseada em uma amostra mais modesta (cerca de 400 empresas, todas com mais de 50 trabalhadores). Neste segundo caso, 58\% das firmas respondentes tinham algum esquema de participação financeira. Ambas as pesquisas concordaram que a PL era mais comum entre os grandes empregadores. Dados comparativos para países da União Européia foram divulgados por um estudo da EPOC de 1996 (Employee Participation in Organizational Change) e, segundo esse trabalho, a incidência de programas de PL era mais baixa na Irlanda do que na média dos países analisados. O índice de PL medido para a Irlanda foi de 8\%, con- 
tra 23\% da média dos países analisados, e o de participação acionária 4\%, contra $9 \%$ da média. O autor afirma que há evidências de que a participação financeira contribui para o aumento da produtividade, especialmente se conjugada com outras formas de envolvimento do trabalhador. Também acredita que a PL tem potencial para auxiliar na estabilização da economia, permitindo a empregados e empresas compartilhar benefícios e riscos de um modo mais flexível.

\section{O CASO BRASILEIRO}

Na primeira vez que a questão entrou em pauta no Brasil, a participação dos trabalhadores nos lucros ou resultados das empresas era um direito do trabalhador estabelecido pela Constituição de 1946, e imposto como "participação obrigatória e direta do trabalhador nos lucros das empresas” (Art. 157, item IV). As reformas constitucionais realizadas em 1967 e 1988 mantiveram esse direito. Na primeira reforma, a PLR passou a ser definida como um direito de "integração do trabalhador na vida e no desenvolvimento da empresa, com participação nos lucros e, excepcionalmente, na gestão, nos casos e condições que forem estabelecidos" (Art. 158, item V). Em 1988, tornou-se direito de "participação nos lucros, ou resultados, desvinculada da remuneração, e, excepcionalmente, participação na gestão da empresa” (Art. 7o, item XI). A PLR era um dos pontos mais novos da Constituição de 1946 no que diz respeito à parte econômica, entretanto, durante os vinte anos de vigência daquela, a PLR não foi regulamentada por lei. O grande obstáculo para a regulamentação parecia ser a exigência constitucional de que a participação fosse direta. Ao quebrar a exigência da participação direta, em 1967, ofereceu-se maior flexibilidade para cada empresa criar seu próprio programa de participação. Essa participação defendida na Constituição não visava primordialmente ao aumento da remuneração do trabalhador, mas, antes disso, à sua "integração na vida e no desenvolvimento da empresa". Em dezembro de 1994 a PLR foi regulamentada pela Medida Provisória 794, sendo depois sucessivamente reeditada, até ser totalmente convertida em lei em dezembro de 2000.

Marinakis (1999) comparou os esquemas de PLR em cinco países latinoamericanos (Chile, México, Peru, Venezuela e Brasil) e, segundo o autor, 
o Brasil era, à época, o único da região que estabelecia por meio legal (MP 794) a possibilidade de negociação da participação nos resultados, com os mesmos benefícios fiscais garantidos para a PL. Nos demais países analisados, o único tipo de participação estabelecido em lei era a participação nos lucros. A característica que mais distinguia o Brasil dos demais, entretanto, era o fato de que o sistema brasileiro dava grande ênfase à necessidade de negociação entre as partes, enquanto os outros sistemas apenas estabeleciam uma fórmula de cálculo e uma aplicação clara.

O México era o único país onde vigoravam os sistemas ditos "puros" de PL, ou seja, era estabelecida por lei uma porcentagem fixa para a determinação da PL, revisada a cada dez anos. Metade do valor da PL deveria ser distribuído igualmente entre os trabalhadores, e os outros 50\% conforme o cargo que ocupavam. O Chile e o Peru, por sua vez, estabeleciam "tetos" para o valor recebido por meio da PL (4,75 salários mínimos no Chile e 18 no Peru). No Peru eram estabelecidos, ainda, diferentes percentuais de participação, de acordo com a atividade econômica. No caso da Venezuela, a lei estabelecia limites inferior e superior para a remuneração da PL. Os máximos estabelecidos eram diferentes para as empresas com número de trabalhadores superior ou inferior a 50 .

A lei 10.101, de 2000, regula a PLR como instrumento de integração entre o capital e o trabalho, e como incentivo à produtividade. A PLR foi transformada em um direito que deve ser negociado entre a empresa e seus empregados, seja por uma comissão mista escolhida pelas partes, seja por uma convenção (negociada no âmbito do setor de atividade) ou acordo coletivo (no âmbito da empresa). Assim, a PLR tornou-se, na prática, um item obrigatório de negociação, mas não um direito garantido do trabalhador. A participação, como já estipulado em lei anterior, não pode substituir ou complementar a renda do trabalhador, e não constitui base para a incidência de qualquer encargo trabalhista. Daí esperava-se gerar o incentivo para a adoção, por parte das empresas, de esquemas de PL.

Para garantir que a empresa não substitua o salário mensal pela PLR, sobre a qual não podem incidir encargos tributários, estipulou-se que a participação não pode ser distribuída em intervalo inferior a seis meses. Diversos critérios podem ser negociados para o cálculo da participação: lucro contábil, resultados econômicos não contábeis (tais como produtividade, 
market share etc.) ou resultados não econômicos (redução no número de faltas, melhoria da qualidade, cumprimento de prazos, entre outros). Para Zylberstajn (2003), a PLR, quando adequadamente negociada, só é paga se as metas estabelecidas forem alcançadas, assim, $\mathrm{o}$ valor da participação pode acompanhar o ciclo de conjuntura. Em períodos de expansão das atividades, cresceriam os lucros das empresas e, em conseqüência, o valor da participação. O oposto deve ocorrer em períodos de recessão.

Na segunda metade da década de 1990, quando as empresas começaram a sentir os efeitos da abertura e a conjuntura da economia brasileira era pouco propícia a ganhos salariais expressivos, os trabalhadores e especialmente os sindicatos passaram a perceber a PLR como uma alternativa aos ganhos salariais permanentes. Os sindicatos também perceberam que a PLR dava aos trabalhadores a oportunidade de influenciar na tomada de algumas decisões das empresas, além das questões estritamente relacionadas à participação. Isso porque, a partir do momento em que a escolha dos resultados que se constituirão como os critérios de avaliação do desempenho da empresa passa a ser deliberada conjuntamente entre representantes dos trabalhadores e da própria empresa, abrem-se espaços inéditos para a discussão de temas relacionados ao ambiente e às condições de trabalho, à tecnologia adotada, à qualificação dos trabalhadores, entre outros.

Em pesquisa realizada pela FIPE - Fundação Instituto de Pesquisas Econômicas, buscou-se avaliar a extensão em que programas de participação nos lucros e resultados eram adotados por empresas brasileiras, e quais as características mais gerais dessas empresas. ${ }^{7}$ Constatou-se uma forte concentração regional e setorial dos esquemas, além de uma grande influência dos sindicatos na decisão de adoção da PLR. A pesquisa contou com uma amostra de 566 empresas, das quais 294 (52\%) disseram apresentar programas de PLR. Destas empresas com esquemas de PLR, 129 pertenciam à indústria metalúrgica e 56 eram da indústria química. Esse número evidencia uma forte concentração dos esquemas da PLR justamente nos setores mais sindicalizados da economia, o que pode indicar que a existência de programas de PLR dependia muito mais da iniciativa dos trabalhadores do que das empresas. Foram analisadas empresas de todos os setores de atividade, desde extração mineral até construção civil, passando por serviços públicos e financeiros. Apesar da dominância em termos numéricos, proporcional- 
mente as metalúrgicas não eram o setor de atividade com maior incidência de programas de PLR. Das três empresas de extração mineral consultadas na pesquisa, todas ofereciam PLR. Em segundo lugar vinham os serviços públicos, com $80 \%$ de respostas positivas em relação à adoção de PLR, seguidos pelas empresas de pneus e artefatos de borracha. Entre as 11 empresas pesquisadas, 8 tinham PLR, perfazendo 73\% de adesão aos esquemas. Metalurgia, elétrica e siderurgia ficaram em quarto lugar, com 69\% das empresas adotando PLR (129 entre as 187 da amostra). A indústria química apareceu em oitavo lugar na pesquisa; 58\% das empresas adotavam PLR (56 de 97).

A PLR foi historicamente mais negociada no setor industrial que nos demais setores, apesar de ter se iniciado uma tendência à desconcentração. De acordo com Zylberstajn (2003), em 1995 o setor industrial era responsável por $86 \%$ dos acordos de PLR notificados. Em 2002, sua participação caiu para $76 \%$ dos casos. Além da concentração setorial, verificava-se também uma forte concentração geográfica dos esquemas de PLR. Em 1995, o Estado de São Paulo concentrava 83\% dos casos de PLR (os demais estados do Sudeste respondiam por 9\%). Sete anos depois, apesar de abrigar ainda a maior parte dos acordos, a representatividade do estado caiu para $51 \%$ do total (com os estados da região Sudeste representando $26 \%$ do total).

Inicialmente, para aceitarem os esquemas de PLR, os sindicatos reivindicavam o pagamento de um bônus aos trabalhadores independentemente dos resultados da empresa. Com o tempo, as empresas conseguiram reverter a situação, e a forma predominante de distribuição passou a ser feita por meio de valores condicionados ao desempenho. Esta mudança parece ter sido benéfica para os trabalhadores, pois os bônus pagos pelas empresas, quando condicionados aos resultados, eram, na maior parte das vezes, superiores àqueles obtidos quando um valor fixo era previamente estabelecido. Quando o pagamento é condicionado a resultados, a empresa não enfrenta riscos, e pode ser mais generosa na gratificação, ao contrário do que ocorre quando ela é obrigada a pagar um bônus fixo aos trabalhadores independentemente de qual seja seu desempenho. Entre 1995 e 2002 aumentaram sensivelmente os acordos de PLR condicionados ao desempenho das empresas; passaram de $58 \%$ para $82 \%$ dos casos. Três tipos de bônus foram encontrados: o primeiro era proporcional ao salário; o segundo, um valor único para todos os trabalhadores; e o terceiro, uma fórmula mista. Em 1995, a maior parte do 
bônus era paga na forma de um valor único (em 51\% dos casos); a partir de 1997, o pagamento de bônus proporcional ao salário passou a ser a forma de distribuição predominante, respondendo por 46\% dos casos em 2002 (contra 33\% de casos de valor único e 18\% de pagamento misto).

A pesquisa de Zylberstajn (2003) aponta para uma clara preferência das empresas por programas de participação em resultados (56\% dos casos em 2002), em relação aos programas mistos, que condicionam o pagamento da participação tanto aos lucros como aos resultados (23\%), e programas puros de participação nos lucros (18\%). O lucro, a síntese dos resultados econômicos da empresa, é o critério menos utilizado no cálculo dos valores das participações. No que diz respeito aos resultados, o mais freqüentemente utilizado é a relação produtividade/produção. Já o cálculo misto pode levar em conta um conjunto de indicadores de venda, faturamentos e a parcela de mercado (market share). Custos e despesas, perdas e refugos e estoques também podem ser levados em consideração pelas empresas em seus cálculos. Os resultados não-econômicos mais freqüentemente levados em consideração são qualidade, satisfação do consumidor, redução no número de faltas e nos atrasos e redução no número de acidentes.

Há ainda pouca pesquisa empírica sobre os efeitos da PL no desempenho das empresas para o caso brasileiro. Zylberstajn (2002) buscou avaliar se a participação nos lucros e resultados das empresas tinha algum impacto sobre a produtividade do trabalho, o comprometimento dos trabalhadores e a relação entre trabalhadores e seus supervisores. ${ }^{8}$ Os resultados do estudo indicam que os pagamentos relacionados ao desempenho tiveram de fato um efeito positivo sobre a produtividade percebida. Dada qualquer parcela de trabalhadores cobertos pelo esquema, a produtividade mostrou-se positiva e significativamente afetada pela participação nos lucros e nos resultados (PLR) quando comparada com os resultados de empresas que ofereciam apenas um bônus bianual, não condicionado a nenhum objetivo estabelecido previamente. Este último tipo de gratificação não afeta o impacto percebido sobre a produtividade. A remuneração relacionada ao desempenho apresenta impactos mais modestos na percepção do comprometimento dos trabalhadores com a empresa e na melhoria das relações entre trabalhadores e seus superiores. $\mathrm{Na}$ amostra de firmas que relataram adotar programas de participação nos lucros e resultados, esses programas foram percebidos 
como um incentivo econômico, afetando positivamente a produtividade do trabalho. Zylberstajn (2002) também notou a expansão dos esquemas de participação no Brasil, como já mencionado anteriormente.

A remuneração dos trabalhadores de acordo com o desempenho é desejável, do ponto de vista da empresa, desde que reduza custos de supervisão e controle, e desde que contribua para a melhoria no ambiente de trabalho e nas relações entre as empresas e seus empregados. Nesse ambiente a empresa tem maiores chances de ser positivamente surpreendida por um aumento de produtividade, na medida em que trabalhadores mais comprometidos com os resultados da firma tendem a despender mais esforços na realização de suas tarefas habituais. $O$ trabalhador também tem a ganhar com este tipo de remuneração, especialmente porque a lei define que sua renda não pode ser prejudicada pela adoção de tais esquemas. Legalmente, a PLR não pode substituir ou mesmo complementar a renda dos trabalhadores. ${ }^{9}$

\section{ALGUMAS LIÇÕES INTERNACIONAIS PARA O CASO BRASILEIRO}

De acordo com o Pepper II ${ }^{10}$ um relatório da Comissão das Comunidades Européias que avaliou o desempenho dos esquemas de PLR entre $1991 \mathrm{e}$ 1996 nos países membros, a rentabilidade trazida pela adoção desses esquemas é flagrante. Segundo o relatório, em todos os casos analisados, a introdução de esquemas de participação esteve associada a aumentos na produtividade das empresas. Outros efeitos positivos também foram encontrados, por exemplo, na flexibilidade dos salários (maior flexibilidade salarial), no emprego e no grau de envolvimento dos trabalhadores. No caso europeu, o desenvolvimento de esquemas de participação financeira foi fortemente influenciado pela ação governamental, sobretudo na França e no Reino Unido, e principalmente através da introdução de incentivos fiscais.

Como conseqüência da crescente competição internacional, as empresas são obrigadas a buscar melhor desempenho, e como o desempenho da empresa está diretamente relacionado ao do trabalhador, as atenções voltaram-se para este. A recompensa aos trabalhadores com base em sua produção, e não nas horas de trabalho, levou a aumentos de lucratividade para as empresas em todos os países avaliados no estudo. A participação nos lucros estava associada a aumentos na produtividade em todos os casos. Os efeitos 
dos esquemas de participação no emprego por meio da maior flexibilidade dos salários não demonstrou resultados convergentes em todos os casos, mas no Reino Unido e na França efeitos positivos foram constatados. As evidências para o caso francês sugerem que a PL resultou de fato em uma maior flexibilidade salarial, que resultou em ajustes no nível de emprego menos freqüentes e em uma taxa de crescimento do emprego maior e mais estável. De acordo com o relatório, tais resultados em relação à produtividade e a flexibilidade salarial têm ao menos dois efeitos que justificam uma maior atenção governamental e a promoção de incentivos para a adoção de tais esquemas: (i) a redução no nível de desemprego e (ii) o aumento do envolvimento entre trabalhadores e empresas, que encoraja uma maior capacitação profissional (maiores investimentos).

As ações governamentais influenciam diretamente a geração e a reprodução de esquemas de participação, na medida em que os governos são os responsáveis pela criação de estruturas legais e fiscais que podem favorecer tais esquemas ou praticamente impedir sua adoção. A prova disso é que naqueles países em que um tipo particular de participação financeira é estimulado por ações governamentais é esse o esquema mais comumente adotado pelas empresas. França e Reino Unido são os dois países que têm maior tradição de incentivo à participação financeira, como já visto anteriormente. Com a exceção desses países, a legislação nos demais membros da UE geralmente favorece a participação acionária. A maior parte da legislação está relacionada a incentivos como vantagens fiscais ou financeiras. Esses incentivos vão desde a isenção de taxas para a emissão de títulos e ações aos trabalhadores até a isenção de taxas sobre os lucros distribuídos. Outra vantagem eventualmente oferecida é a isenção de contribuições de seguridade social.

Desde o fim dos anos 50 o governo francês estimula a introdução de esquemas de participação financeira nas empresas do país, e por isso a França tem hoje estrutura legal e vantagens fiscais atrativas para todos os tipos de esquemas de participação. Entre 1993 e 1994 novas iniciativas legais foram adotadas, com o objetivo de simplificar a legislação e alargar os incentivos fiscais. Além de manter os benefícios fiscais que já existiam, a lei de 1994 aumentava de modo particular as vantagens para os chamados planos de PL "diferidos" (deferred profit sharing plans) - nesses planos, uma porcentagem dos lucros é alocada em um fundo da companhia e é depois investida 
em nome dos empregados, tendo como objetivo encorajar investimentos e reduções de custos no longo prazo. Ao mesmo tempo, a lei estimulava o consumo de curto prazo. Os salários base na França não podem ser substituídos ou complementados pela PL; antes, a PL fornece ao trabalhador um adicional ao salário base, conforme alguma medida previamente estabelecida do desempenho da firma. Os cálculos para a distribuição das participações também devem ser os mesmos para qualquer categoria de empregado dentro da firma. A França é o único país europeu onde esquemas de participação nos lucros são obrigatórios para empresas que ultrapassam um certo tamanho. Aquelas cujo número de trabalhadores empregados excede 50 devem oferecer a seus trabalhadores algum esquema de PL. Os trabalhadores, porém, só podem dispor de sua parte depois de três ou cinco anos na empresa. O estudo realizado pela EPOC (Employee Participation in Organizational Change) estima que, em 1996, 57\% dos estabelecimentos na França tinham algum programa de participação nos lucros.

Além das adaptações feitas às antigas propostas, a lei de 1994 ainda introduziu novas medidas, inspirada na "democracia industrial" e no desenvolvimento macroeconômico, como: (i) o estímulo à participação dos empregados que detêm títulos e ações das empresas no gerenciamento das firmas; (ii) a possibilidade de introdução de uma "conta de economia de tempo" por acordo coletivo, que permite aos empregados converter seus bônus de PL em redução de carga horária; (iii) a possibilidade de a companhia "descongelar" os fundos de PL para a compra de novos veículos ou para trabalhos de construção; e (iv) a criação do Conselho Superior de Participação (CSP), que demonstra a importância da questão da PL para o governo francês. As principais responsabilidades e atribuições desse Conselho são fiscalizar a aplicação da participação financeira e da participação na gerência nas empresas, coordenar as iniciativas que levem a uma maior extensão desses programas, além de elaborar um relatório anual para o governo resumindo todos os avanços nos planos de participação financeira e na barganha salarial para aquelas empresas que adotaram de maneira voluntária esses acordos.

Ao lado da França, o Reino Unido é o país onde os esquemas de participação financeira são mais fortemente incentivados pelo governo. A tradição da participação financeira é longa no país, e teve forte crescimento a partir 
de 1978, quando a legislação passou a garantir concessões fiscais para esquemas de PL e participação acionária. Ao contrário da França, entretanto, os esquemas no país são adotados de forma voluntária pelas empresas e pelos empregados. Empregados e empregadores podem decidir qual esquema de participação financeira é mais conveniente para a realidade da empresa e suas necessidades particulares. No Finance Act de 1995 foram introduzidas mudanças nos critérios de elegibilidade para os cinco esquemas de participação financeira. As mudanças foram feitas no sentido de retirar as restrições anteriores na inclusão de trabalhadores de meio-período, que passaram a ter qualificação para participar dos esquemas. O Finance Act de 1996 criou a Company Share Option Plan, para os proprietários que estavam nos intervalos de renda baixa e média. Também foram feitos outros melhoramentos para os demais esquemas de participação, no intuito de torná-los mais flexíveis e atrativos tanto para empregados como para empregadores.

Para os trabalhadores ingleses, os esquemas de participação trazem grandes vantagens. Esses planos lhes permitem receber o montante devido sem taxação ou com uma taxação bastante reduzida, sem pagar imposto de renda sobre o valor recebido dessa maneira. Os custos em que a companhia incorre para instalar os esquemas também são dedutíveis de impostos. Existem no Reino Unido três tipos de esquemas aprovados: os dois primeiros implicam que todos os funcionários de uma empresa com mais de cinco anos de serviço devem ter a permissão de participar do esquema de participação; o terceiro tipo permite à firma restringir a participação a empregados selecionados, de acordo com as regras estipuladas pelo empregador. As participações também podem ser transferidas aos trabalhadores por um programa chamado "employee share ownership trust", no qual a companhia estabelece um truste que adquire e distribui a participação aos empregados. Esse truste é responsável por comprar e vender as participações e distribuílas aos trabalhadores.

O governo do Reino Unido sustenta um grande número de iniciativas para promover a participação financeira e está envolvido de maneira ativa na disseminação de informações e na promoção de práticas corretas de esquemas de participação. O governo esteve atento à necessidade de melhorar a informação sobre os incentivos fiscais e os benefícios da adoção dos esquemas, especialmente entre as empresas pequenas e nos setores não-serviços. 
Uma campanha governamental foi lançada, e nela, colocada em evidência a necessidade de integração entre os esquemas de participação e a integração do trabalhador na empresa.

As bem-sucedidas experiências francesa e britânica mostram que o papel do governo na produção de incentivos aos planos de participação financeira e no esclarecimento sobre suas vantagens são peças fundamentais para a expansão desses esquemas sem a deturpação de suas finalidades. Um dos benefícios potenciais dos esquemas de PL é sua capacidade de contribuir para estabilizar a economia em um nível mais elevado de emprego. Isso aconteceria porque, especialmente em períodos de recessão, o ajuste desencadeado pela queda na demanda seria feito pela compressão da massa de pagamento, e não do nível de emprego. Em um país como o Brasil, onde o problema do desemprego é crítico, essa pode ser uma maneira de atenuar os efeitos de um período de crise.

Outro benefício potencial dos esquemas de participação é o aumento da produtividade. O mecanismo que justifica esta suposição já foi enfatizado anteriormente. $\mathrm{O}$ fato de a PL poder contribuir para o aumento da produtividade, contudo, não justifica o apelo pela intervenção governamental no sentido de oferecer isenção fiscal para tais rendimentos. Isso porque os benefícios da maior produtividade geralmente serão apropriados privadamente, tanto pelos empregadores como pelos empregados. O incentivo governamental se justifica mesmo neste caso, no entanto, pelo fato de que, geralmente, empregados e empregadores não têm uma visão muito clara dos benefícios desse tipo de programa, não arriscando adotá-lo a menos que tenham incentivos externos. As evidências encontradas em muitos dos trabalhos analisados sugerem que os benefícios sobre a produtividade associados à PL são maiores quando combinados a outras formas de envolvimento dos trabalhadores. Quanto maior a identificação do trabalhador com a firma, maior tende a ser seu empenho para melhorar os resultados dela.

Apesar da lei que define como direito do trabalhador a negociação da participação nos lucros e resultados das empresas, o governo brasileiro pouco tem feito para incentivar de modo efetivo a adoção de tais esquemas. Essa morosidade em relação à transformação da proposta da lei em participação de fato para os trabalhadores é uma característica que vem se mantendo há décadas. Como se viu, desde 1946 a participação dos trabalhadores nos 
lucros e resultados das empresas é garantida por lei, mas em 2002 ainda era baixa a proporção de trabalhadores que usufruíam tal benefício. A concentração regional e setorial dos esquemas também é sinal de que a proposta não se faz cumprir de fato, e somente quando os trabalhadores têm força para reivindicar seu direito é que a participação tem chance de se concretizar. O empenho dos governos europeus, especialmente dos governos francês e inglês, em incentivar a PLR deveria ser entendido como um sinal de que as conseqüências positivas da implementação de tais esquemas justificam todo o esforço aplicado. A Europa, como se sabe, também é uma região que sofre com taxas elevadas de desemprego, e apresenta custos de trabalho elevados. $\mathrm{O}$ aumento da produtividade que tende a acompanhar a introdução dos esquemas de PL reforça a competitividade das empresas da região e atenua os efeitos negativos do alto custo da mão-de-obra. Em relação ao desemprego, já foi mostrado pelo relatório da Comissão Européia que na França, com o crescimento dos esquemas de PL cresceu também a estabilidade do emprego. A maior flexibilidade salarial levou a ajustes menos freqüentes no nível de emprego e a um maior e mais estável crescimento do emprego. O maior comprometimento dos trabalhadores com as firmas, que poderia gerar maiores incentivos a investimentos em capital humano, melhorando a qualificação da mão-de-obra no país, também deve ser levado em consideração. Esses resultados deveriam justificar um maior empenho do governo brasileiro para a conscientização e popularização dos esquemas de PLR, que poderiam trazer ao país maior produtividade, melhores condições e relações de trabalho dentro das fábricas, maior estabilidade no nível de emprego e trabalhadores mais qualificados.

NOTAS

1. A participação acionária é um modo de participação fundamentalmente diferente da PL, na medida em que concede aos trabalhadores, em alguma medida, mecanismos de participação nas decisões gerenciais.

2. A versão final do questionário elaborado pelos autores foi enviada para os diretores de RH das 2.127 firmas japonesas listadas na HRM Survey of Japanese Firms. A taxa de respostas foi de 17\%, taxa similar àquelas obtidas por pesquisas de natureza semelhante no país. Os autores consideram apenas os sistemas de pagamentos de bônus com contratos formais estipulando a presença dos planos de participação nos lucros. 
3. Conforme Chelius e Smith (1990: 262), trata-se de "plans under which share distributions are paid into an account to which the employee has only limited access until separation or retirement".

4. Os autores compararam os resultados de empresas que adotavam em relação às que não adotavam ESOPs (Employee Share Ownership Plans), planos em que a participação acionária dos trabalhadores era controlada por meio de um comitê.

5. Os autores comparam o desempenho de empresas antes e depois da adoção de um ESOP.

6. O pagamento de LS pode também ser condicionado a alguma medida de desempenho, e é geralmente associado a algum tipo de concessão salarial, o que sugere, segundo os autores, que os trabalhadores podem ser coibidos a aceitá-lo. Para Uchitelle (1989), entretanto, os trabalhadores parecem gostar do esquema de LS.

7. Dados obtidos pelo programa Mediar - Informações para a Mediação Estratégica entre Trabalho e Capital. A pesquisa foi realizada em dezembro de 1997, e na amostra foram coletados cerca de 1.700 convenções e acordos coletivos. O Mediar era parte de um projeto de pesquisa constante, que produzia e enviava questionários mensais para firmas e uniões trabalhistas.

8. Novamente foram utilizados dados do projeto Mediar.

9. Na prática, porém, muitas vezes isso acontece e, na negociação anual da correção salarial, em vez de reajustar os salários de seus funcionários conforme o índice de inflação, muitas empresas preferem negociar abonos (PLR). Vale lembrar que, em 1995, foi reeditada a medida provisória que dispunha sobre a participação dos trabalhadores nos lucros e resultados nas empresas (MP 1029), enquanto se buscava consolidar políticas de estabilização. No mesmo ano foi transformada em lei a MP 1053, que entre outras medidas vedava a estipulação ou a fixação de cláusula de reajuste ou correção salarial automática vinculada a índices de preços, e a concessão a título de produtividade de aumento não amparado em indicadores objetivos. Foram assim suprimidos os instrumentos legais que possibilitavam a reposição das perdas salariais e o aumento real dos salários, e incentivaram-se remunerações com parte variável cada vez maior, e parte fixa cada vez menor.

10. Promotion of Participation by Employed Persons in Profits and Enterprise Results in Member States.

\section{REFERÊNCIAS BIBLIOGRÁFICAS}

AZFAR, O., DANNINGER, S. (2001) "Profit-Sharing, Employment Stability, and Wage Growth”, Industrial and Labor Relations Review, v. 54, n. 3, p. 619-630.

BELL, D., HANSON, C. (1987) Profit-sharing and profitability: How Profit-Sharing Promotes Business Success. Londres: Kogan Page. 
BELL, L. A., NEUMARK, D. (1993) “Lump-sum payments and profit-Sharing plans in the union sector of the United States Economy”, The Economic Journal, v. 103, n. 418, p. 602-619.

BHARGAVA, S. (1994) "Profit-Sharing and the financial performance of companies: evidence from U.K. panel data”, The Economic Journal, v. 104, n. 426, p. 1044-1056.

BLANCHFLOWER, D. G., OSWALD, A. J. (1988) “Profit-related pay: prose discovered?”, The Economic Journal, v. 98, n. 392, p. 720-730.

CABLE. J., WILSON, N. (1989) "Profit-Sharing and productivity: an analysis of the UK engineering firms”, The Economic Journal, v. 99, n. 396, p. 366-375.

(1990) "Profit-Sharing and productivity: some further Evidence", The Economic Journal, v. 100, n. 401, p. 550-555.

CAHILL, N. (2000) "Profit-Sharing, Employee Share Ownership and Gainsharing: What Can They Achieve?”. Research Series Paper n. 4, National Economic and Social Council.

CAHUC, P., DORMONT, B. (1997) “Profit-Sharing: Does it increase productivity and employment? A Theoretical model and Empirical evidence on French micro data", Labour Economics 4, p. 293-319.

CHELIUS, J., SMITH, R. S. (1990) "Profit-Sharing and Employment Stability", Industrial and Labor Relations Review, v. 43, n. 3, p. 256-273.

COMISSÃO EUROPÉIA (1996) PEPPER II, "Promotion of Participation by Employed Persons in Profits and Enterprises Results (including equity participation) in Member States". Commission of the European Communities, Bruxelas.

ESTRIN, S., PÉROTIN, V., ROBINSON, A., WILSON, N. (1997) "Profit-Sharing in OECD Countries: a Review and Some Evidence”, Business Strategy Review, v. 8, p. 27-32.

FITZROY F. R., KRAFT, K. (1986) "Profitability and profit-sharing", The Journal of Industrial Economics, v. 35, n. 2, p. 113-130.

(1987) “Cooperation, productivity and profit-Sharing”, The Quarterly Journal of Economics, v. 102, n. 1, p. 23-35.

FUNG, K. C. (1989) "Profit-Sharing and the european unemployment", European Economic Review, v. 33, n. 9, 1787-1798.

GOTTFRIES, N., SJÖSTRÖM, T. (1995) "Profit-sharing, employment efficiency and wage stability", Scandinavian Journal of Economics.

KATO, T., MORISHIMA, M., "The nature, scope and effects of profit sharing in Japan: evidence from new survey data", International Journal of Human Resource Management, v. 14, n. 6, Sept.

KIM, S. (1998) “Does profit-sharing increase firm profits?", Journal of Labor Research, v. 19, n. 2, p. 351-370.

KRUSE, D. (1992) "Profit-sharing and productivity: microeconomic evidence from the United States”, The Economic Journal, v. 102, n. 410, p. 24-36.

(1993) “Profit-sharing: does it make a difference?", Journal of Economics Issue, v. 28, n. 2 . 
KRUSE, D., BLASI, J. (1997) "Employee Ownership, Employee Attitudes and Firm Performance: A Review of the Evidence". In: D. Lewin, D. Mitchell, M. Zaidi, The Human Resource Management Handbook. JAI Press.

LEVINE, D., TYSON, L. (1990) “Participation, Productivity and the Firm's Environment”. In: A. Blinder, Paying for Productivity, A Look at the Evidence. Washington, DC: The Brookings Institution.

MARINAKIS, A. E. (1999) "Participación de los trabajadores en las utilidades o resultados de las empresas en América Latina”, Revista de la Cepal, n. 69, p. 71-84.

QUARREY, M., ROSEN. C. (1997) Employee Ownership and Corporate Performance. Oakland: National Centre for Employee Ownership.

THERRIEN, P., LÉONARD, A. (2003) “Empowering employees: A route to innovation”. Statistics Canada, Human Resources Development.

TSEO, G. K., SHENG, H. G., PENG-ZHU, Z., LIHAI, Z. (2004) “Employee ownership and profitsharing as positive factors in the reform of chinese state-owned enterprises", Economic and Industrial Democracy, v. 25 (1), p. 147-177.

WADHWANI, S. B. (1987) “The macroeconomic implications of profit-sharing: some empirical evidence”, The Economic Journal, v. 97, Supplement: Conference Papers, p. 171-183.

WADHWANI, S., WALL, M. (1990) “The effects of profit-sharing on employment, wages, stock returns and productivity: Evidence from UK micro data", The Economic Journal, v. 100, p. $1-17$.

WEITZMAN, M. (1984) The Share Economy. Cambridge: Harvard University Press.

ZYlBeRstajN, H. (2002) “The Brazilian Case: Performance Pay as Worker's Right”. In: M. Brown, J. S. Heywood, Paying for Performance, An International Comparison. M. E. Sharp, p. 236-260.

(2003) "Participação dos empregados nos lucros ou nos resultados das empresas - um balanço da negociação: 1995-2002”. In: J. P. Z. Chahad, P. Picchetti (org.), Mercado de trabalho no Brasil. LTR Editora. 